\title{
Edwardsiella tarda bacteremia. A rare but fatal water- and foodborne infection: Review of the literature and clinical cases from a single centre
}

\author{
Yuji Hirai MD PhD ${ }^{1,2}$, Sayaka Asahata-Tago MD ${ }^{1}$, Yusuke Ainoda MD PhD ${ }^{1}$, \\ Takahiro Fujita MD PhD ${ }^{1}$, Ken Kikuchi MD PhD ${ }^{1}$
}

Y Hirai, S Asahata-Tago, Y Ainoda, T Fujita, K Kikuchi. Edwardsiella tarda bacteremia. A rare but fatal water- and foodborne infection: Review of the literature and clinical cases from a single centre. Can J Infect Dis Med Microbiol $2015 ; 26(6): 313-318$.

BACKGROUND: Edwardsiella tarda bacteremia (ETB) can be a fatal disease in humans.

OBJECTIVES: To determine the significant risk factors associated with death caused by ETB, and to examine the geographical, seasonal, environmental and dietary factors of the disease.

METHODS: A retrospective, observational, case control study was performed. The PubMed MEDLINE and Japanese Medical Abstract Society (www.jamas.or.jp) databases were searched for ETB case reports and meeting abstracts. In additon, retrospective chart reviews of patients with ETB at the Tokyo Women's Medical University Hospital (Tokyo, Japan) were conducted to evaluate the risk factors associated with death using multivariate analyses.

RESULTS: The literature search yielded 46 publications, comprising 72 cases from the English $(n=30)$, French $(n=1)$, Spanish $(n=1)$ and Japanese $(n=14)$ literature. Five cases at the Tokyo Women's Medical University Hospital were also included. Of the included 77 cases, the mean age was 61 years and $39 \%$ of patients were female; $77.2 \%$ of the cases occurred between June and November, and $45.5 \%$ were reported in Japan. Dietary factors (raw fish/meat exposure) were reported for $10.4 \%$ of patients and $12.9 \%$ reported environmental (ie, brackish water) exposure. The overall mortality rate was $44.6 \%$; however, this rate increased to $61.1 \%$ for ETB patients with soft tissue infections. Liver cirrhosis was determined to be an independent risk factor associated with death (OR 12.0 [95\% CI 2.46 to 58.6]; $\mathrm{P}=0.00213$ ) using multivariate analyses. DISCUSSION: To our knowledge, the present analysis was the first and largest multi-language review of ETB. Clinical characteristics of ETB resemble those of Aeromonas, typhoid fever and Vibrio vulnificus infections, in addition to sharing similar risk factors.

CONCLUSION: ETB should be categorized as a severe food- and waterborne infection, which results in high mortality for patients with liver cirrhosis.

Key Words: Bacteremia; Edwardsiella tarda; Foodborne infection; Food habits; Liver cirrhosis; Risk factors; Waterborne infection

\author{
La bactériémie à Edwardsiella tarda. Une infection \\ d'origine hydrique et alimentaire, mais fatale : \\ analyse bibliographique et cas cliniques dans un \\ seul centre
}

HISTORIQUE : Chez les humains, la bactériémie à Edwardsiella tarda (BET) peut être mortelle.

OBJECTIFS : Déterminer les facteurs de risque importants liés aux décès causés par la BET et examiner les facteurs géographiques, saisonniers, environnementaux et diététiques de la maladie.

MÉTHODOLOGIE : Les chercheurs ont effectué une étude castémoins d'observation rétrospective. Ils ont fait des recherches dans les bases de données MEDLINE de PubMed et de la Société japonaise de communications médicales (www.jamas.or.jp) pour trouver les comptes rendus de BET et les communications de cas lors de colloques et congrès. Ils ont également procédé à une analyse rétrospective des dossiers de patients atteints d'une BET à l'hôpital universitaire de Tokyo pour femmes, au Japon, pour évaluer les facteurs de risque liés aux décès à l'aide d'analyses multivariées.

RÉSULTATS : L'analyse bibliographique a permis d'extraire 46 publications, soit 72 cas tirés de publications anglophones $(n=30)$, francophones $(n=1)$, espagnoles $(n=1)$ et japonaises $(n=14)$. Cinq cas de l'hôpital universitaire de Tokyo pour femmes étaient également inclus. Les 77 cas avaient un âge moyen de 61 ans, et $39 \%$ étaient de sexe féminin, $77,2 \%$ s'étaient déclarés entre les mois de juin et novembre et $45,5 \%$ provenaient du Japon. Chez 10,4 \% des patients, des facteurs diététiques (poisson cru, exposition à la viande) étaient en cause, tandis que 12,9\% présentaient une exposition environnementale (eau saumâtre). Le taux de mortalité globale s'élevait à 44,6\%, mais passait à $61,1 \%$ chez les patients atteints d'une BET et d'infections des tissus mous. D'après les analyses multivariées, la cirrhose était un facteur de risque indépendant de décès (RC 12,0 [95 \% IC 2,46 à 58,6]; P=0,00213).

EXPOSÉ : En autant que nous le sachions, il s'agissait de la plus vaste analyse sur la BET et de la première à être multilingue. Les caractéristiques cliniques de la BET ressemblent à celles des infections à Aeromonas et à Vibrio vulnificus et de la typhoïde en plus de partager des facteurs de risque similaires.

CONCLUSION : La BET devrait être classée parmi les graves infections d'origine hydrique et alimentaire qui entraînent des taux de mortalité élevés chez les patients atteints d'une cirrhose.

E tarda is typically isolated from fresh or brackish water environments such as river mouths. It has also been isolated from the intestines of humans (after eating fresh water food sources such as catfish [5] or eels [6]) and from animals, including reptiles and freshwater fish.

E tarda rarely causes infections in humans. The colonization rate in humans ranges from $0.0073 \%$ in the Japanese (7) to $1 \%$ in Panamanians (8). Approximately $80 \%$ of $E$ tarda infections in humans are characterized
Cdwardsiella tarda is a motile, facultatively anaerobic, Gram- negative rod that is categorized as a member of the family Enterobacteriaceae. The genus Edwardsiella was first recognized by Trabulsi et al (1) in 1962, followed by a description of $E$ tarda in the mid-1960s. These organisms have successively been named the "Bartholomew group" by King and Adler (2), the "Asakusa group" by Sakazaki (3) and "Edwardsiella" by Ewing et al (4).
${ }^{1}$ Department of Infectious Diseases, Tokyo Women's Medical University; ${ }^{2}$ Department of General Medicine, Faculty of Medicine, Juntendo University, Toyko, Japan

Correspondence: Dr Yuji Hirai, Department of Infectious Diseases, Tokyo Women's Medical University, 8-1 Kawada-cho, Shinjuku, Tokyo 162-8666, Japan. Telephone 81-3-3353-8112 ext 28924, fax 81-3-3358-8995, e-mail: hirai.yuji@twmu.ac.jp 
TABLE 1

Clinical characteristics of 77 patients with Edwardsiella tarda bacteremia (ETB)

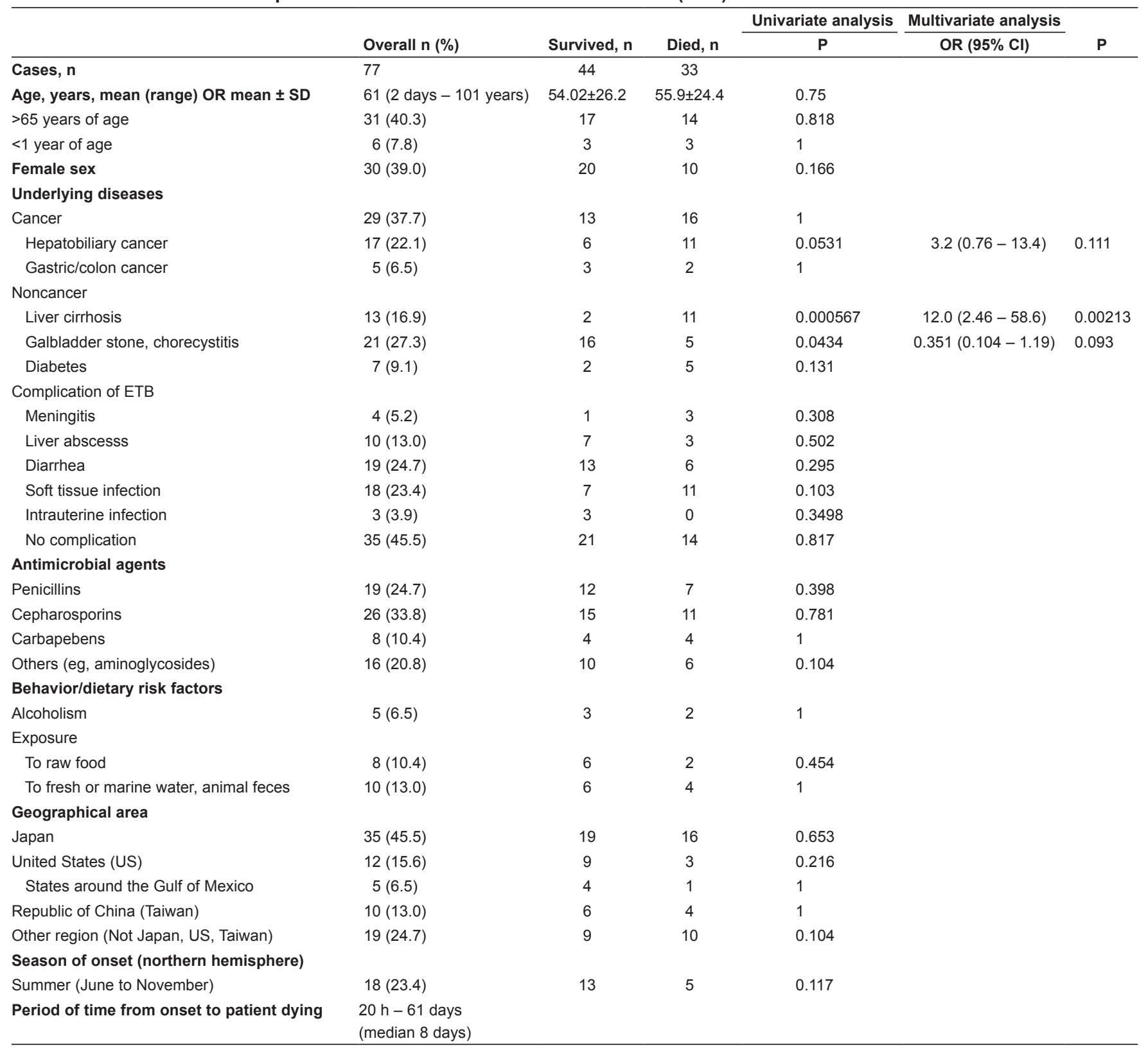

as gastroenteritis and E tarda is primarily isolated from stool samples. Extraintestinal infections, such as endocarditis, empyema, hepatobiliary infections, peritonitis, intra-abdominal abscesses, osteomyelitis, wound infections and meningitis, have been reported less frequently. While E tarda bacteremia (ETB) occurs relatively rarely $(<5 \%)$, it can be fatal in humans (9). However, little is known about the clinical epidemiology of ETB. Therefore, we aimed to document the clinical epidemiology of ETB, including independent risk factors associated with death, the geographical and seasonal distributions, as well as environmental and dietary risks, based on previous reports and recent clinical cases of ETB at our institution (Tokyo Women's Medical Univeristy [TWMU] Hospital [Tokyo, Japan]).

\section{METHODS}

A retrospective, observational, case control study was performed. The present analysis comprised literature and retrospective chart reviews. A search was conducted for case reports and case series involving ETB, published between January 1968 and December 2013, with the PubMed MEDLINE and Japanese Medical Abstracts Society ICHUSHI (www.jamas.or.jp) databases using the following keywords: "Edwardsiella tarda", "E tarda" and "infection". An episode of ETB was defined as $\geq 1$ positive blood cultures yielding E tarda from the same patient. Results meeting the following criteria were included: published case reports or abstracts from scientific meetings; patients of any age; and articles published in any language including English, French, Spanish and Japanese. Exclusion criteria included: negative blood culture; no description of $E$ tarda infection; animal cases; experimental studies; and review articles.

In addition, the medical records of patients, regardless of age, with ETB admitted to the TWMU (a 1423-bed university hospital in Tokyo, Japan) between April 2000 and December 2013, were included in the retrospective chart review.

The following data were obtained from both published and TWMU-admitted cases that fulfilled the inclusion criteria: age; sex; underlying disease; antibiotic treatment; complications related to the ETB; geographical area; month of ETB onset; history of exposure to 
TABLE 2

Antimicrobial susceptibility of Edwardsiella tarda isolated from blood culture; five cases from Tokyo Women's Medical University (TWMU; Tokyo, Japan) and eight cases from the literature

\begin{tabular}{|c|c|c|c|c|c|c|c|c|c|c|c|c|c|c|}
\hline \multirow{2}{*}{$\begin{array}{l}\text { Age, } \\
\text { years/sex }\end{array}$} & \multirow{2}{*}{$\begin{array}{l}\text { Underlying } \\
\text { disease(s) }\end{array}$} & \multirow[b]{2}{*}{ Complication } & \multirow{2}{*}{$\begin{array}{l}\text { Exposure/ } \\
\text { dietary risk }\end{array}$} & \multicolumn{8}{|c|}{ Minimum inhibitory concentration (MIC), mg/L } & \multirow{2}{*}{$\begin{array}{c}\text { TWMU } \\
\text { case or } \\
\text { reference }\end{array}$} & \multirow[b]{2}{*}{ Country } & \multirow[b]{2}{*}{ Year } \\
\hline & & & & ABPC & CEZ & CTX & IPM/CS & GM & LVFX & TMP-SMX & Colistin & & & \\
\hline $88 /$ female & GBS & Cholecystitis & ND & $<2$ & $<2$ & $<8$ & $<1$ & $<1$ & $<0.5$ & $<2$ & $16(\mathrm{R})$ & TWMU-1 & Japan & 2004 \\
\hline $80 /$ male & $\mathrm{LC}, \mathrm{HCC}$ & EC & ND & $<2$ & $<2$ & $<8$ & $<1$ & $<1$ & $<0.5$ & $<2$ & $24(\mathrm{R})$ & TWMU-2 & Japan & 2004 \\
\hline $84 /$ male & $\mathrm{BCa}$ & Cholecystitis & ND & $<4$ & $<4$ & $<8$ & $<1$ & $<1$ & $<2$ & $<2$ & $32(\mathrm{R})$ & TWMU-3 & Japan & 2010 \\
\hline 80/female & $\mathrm{PCa}$ & Liver abscess & ND & $<4$ & $<4$ & $<8$ & $<1$ & $<1$ & $<2$ & $<2$ & $0.125(\mathrm{~S})$ & TWMU-4 & Japan & 2013 \\
\hline 46/female & $\mathrm{Ce}-\mathrm{Ca}$ & EC & Sushi & $<4$ & $<4$ & $<8$ & $<1$ & $<1$ & $<2$ & $<2$ & $32(\mathrm{R})$ & TWMU-5 & Japan & 2013 \\
\hline 14/female & none & Liver abscess & Immigrant & $\mathrm{S}$ & ND & ND & ND & ND & ND & ND & $\mathrm{R}$ & 13 & Thailand & 1969 \\
\hline 46/male & none & EC & $\begin{array}{l}\text { Travel to } \\
\text { Mexico }\end{array}$ & 0.25 & $\begin{array}{c}1 \\
\text { (cefalothin) }\end{array}$ & ND & ND & 0.25 & ND & ND & $\mathrm{R}$ & 18 & $\begin{array}{l}\text { United } \\
\text { States }\end{array}$ & 1980 \\
\hline $39 /$ male & Alcoholism & EP, DC & ND & $S$ & S & $S$ & $S$ & S & $S$ & $S$ & ND & 41 & Japan & 1988 \\
\hline $67 /$ male & HCC,LC & NF & ND & S & $\mathrm{S}$ & $\mathrm{S}$ & $\mathrm{S}$ & $\mathrm{S}$ & $\mathrm{S}$ & $\mathrm{S}$ & ND & 42 & Japan & 1996 \\
\hline 76/male & $\mathrm{DM}, \mathrm{HCC}$ & Liver abscess & Sushi & ND & $<8$ & $\begin{array}{c}<8 \\
(\mathrm{CAZ})\end{array}$ & $\begin{array}{c}<1 \\
(\mathrm{MEPM})\end{array}$ & $\begin{array}{c}<16 \\
(\mathrm{AMK})\end{array}$ & $<2$ & ND & ND & 51 & Japan & 2011 \\
\hline $21 /$ female & SCA & None & ND & $<2$ & $<4$ & $<0.5$ & $<1$ & 2 & $<0.25$ & $<2$ & ND & 39 & Columbia & 2008 \\
\hline 46/female & SLE & PID & ND & $<2$ & $<4$ & $<1$ & $<1$ & $<1$ & $<0.12$ & ND & ND & 53 & Japan & 2012 \\
\hline 67/female & $\mathrm{NHL}$ & $\mathrm{NF}$ & ND & $<4$ & $<4$ & $<8$ & $<1$ & $<1$ & $<1$ & $<2$ & ND & 52 & Japan & 2012 \\
\hline
\end{tabular}

ABPC Ampicillin; AMK Amoxicillin; BCa Bile duct cancer; CAZ Ceftazidime; Ce-Ca Cervical cancer; CEZ Cefazolin; CTX Cefotaxime; DC Discitis; DM Diabetes mellitus; EC Endstage cancer; EP Endophthalmitis; GBS Gallbladder stone; GM Gentamicin; HCC Hepatiocellular carcinoma; IPM/CS Imipenem cilastatin; LC Liver cirrhosis; LVFX Levofloxacin; MEPM Meropenem; ND Not described; NF Neurofibromatosis; NHL Non-Hodgkin lymphoma; PCa Pancreatic cancer; PID Pelvic inflammatory disease; $R$ Resistant (MIC not described); S Susceptible (MIC not described); SCA Sickle cell anemia; SLE Systemic lupus erythematosus; TMP-SMX Trimethoprim/sulfamethoxazole

environmental risk factors; dietary history to include dietary risk factors; and crude mortality after ETB within 90 days. The case definition for survival required a report of whether the patient survived, or no report of death, in published articles or medical records from cases at TWMU. During the study period, 112,796 blood samples were obtained under sterile conditions and were processed using BACTEC 9240 (Becton Dickinson Diagnostic Instrument Systems, USA) until March 11, 2011, and BacT/ALERT 3D (bioMérieux, France) from April 2011 onward. Strains of E tarda were identified using MicroScan WalkAway 96si (Siemens, Germany). The five cases of ETB identified were included in the present study. The species identification of E tarda was also confirmed using matrix-assisted laser desorption ionization-time of flight mass spectrometry (Microflex LT with MALDIBiotyper version 3.1, Bruker Daltonik, Germany). Susceptibility of E tarda isolated from blood cultures was tested retrospectively in accordance with the standards of the Clinical and Laboratory Standards Institute using E-test (bioMérieux, France).

Continuous data were compared using a $t$ test and categorical data were compared using Fisher's exact tests; $\mathrm{P}<0.05$ was considered to be statistically significant. Multivariate analyses were used to determine the independent risk factors associated with mortality using forward stepwise logistic regression. All variables with $\mathrm{P}<0.1$ in univariate analyses were entered into the multivariate model. Statistical analyses were performed using $\mathrm{R}$ version 3.0.3 (www.r-project.org).

The study protocol was approved by the TWMU Hospital Medical Ethics Committee (No. 3052).

\section{RESULTS}

The literature search resulted in 234 articles from the PubMed MEDLINE database and 68 articles from the ICHUSHI database, published between January 1968 and December 2013. Of these, 202 and 54 publications were excluded, according to inclusion criteria, from the PubMed MEDLINE and ICHUSHI databases, respectively. The resulting 46 publications, published between 1968 and 2013, were retrieved from the English $(n=30)(8-37)$, French $(n=1)$ (38), Spanish $(n=1)(39)$ and Japanese $(n=14)$ literature $(40-53)$. A total of 72 cases were described in the retrieved publications and five cases diagnosed at the TWMU were also included, resulting in 77 cases for analysis.
The mean age of the patients was 61 years (range two days to 101 years) and 30 cases (30 of 77 [39\%]) involved women. Underlying diseases included cancer (29 of 77 [37.6\%]); hepatobiliary cancer (17 of 77 [20.8\%]) and liver cirrhosis (13 of 77 [16.8\%]). Six $(6.5 \%)$ cases involved neonatal patients. Thirteen $(16.9 \%)$ cases occurred in healthy individuals without any underlying disease and there were $35(45.5 \%)$ cases of uncomplicated ETB. Eighteen $(23.4 \%)$ cases involved soft tissue infections, $24.7 \%$ involved diarrhea, $13.0 \%$ involved liver abscess and $3.9 \%$ involved meningitis. Despite appropriate antimicrobial therapy, the overall mortality rate was $44.6 \%$ (33 of 74 , no mortality data available for three cases $[14,46,49]$ ); however, this rate increased to $61.1 \%$ (11 of 18 ) for patients with soft tissue infections.

Treatment using the following antimicrobial agents was described in 51 cases $(66.2 \%)$ : cephalosporin $(n=26)$, penicillin $(n=19)$ and carbapenems $(n=8)$. Although no significant differences were found with respect to age, sex, complications of ETB, geographical area or season of onset among cases in which the patient died compared with cases in which the patient survived, liver cirrhosis (OR $12.0[95 \% \mathrm{CI}$ 2.46 to 58.6]; $\mathrm{P}=0.00213$ ) was considered to be an independent risk factor associated with death in multivariate analyses (Table 1). Antibiotic susceptibility of the E tarda strains that were isolated from the blood cultures is summarized in Table 2. Six cases in the literature reported susceptibility to ampicillin, cefazolin, imipenem, levofloxacin and gentamicin, in cases in which each drug minimum inhibitory concentrations were measured $(13,18,39,41,42,51-53)$. Reduced susceptibility to colistin was found in four of five strains $(80 \%)$ at the TWMU and two of two strains $(13,18)$ in the literature. Reported environmental risks included direct exposure to fresh or brackish water (lacerated forearm after a fall into brackish water [28] and fishing $[28,36]$ ), soil (farming [8] and gardening [12]) and animal feces (working in a zoo [20]). The parents of two neonatal cases were exposed to fresh water; the father from one case was a dock maintenance worker at a lake and his wife participated in a baptism involving immersion in a lake while pregnant, and a mother from another case washed clothes in a river resulting in confirmed maternal colonization $(29,50)$. Reported dietary risks included exposure to raw fish/sushi $(48,50,51)$ (TWMU-5 in Table 2), raw meat (27), ceviche during a trip to 


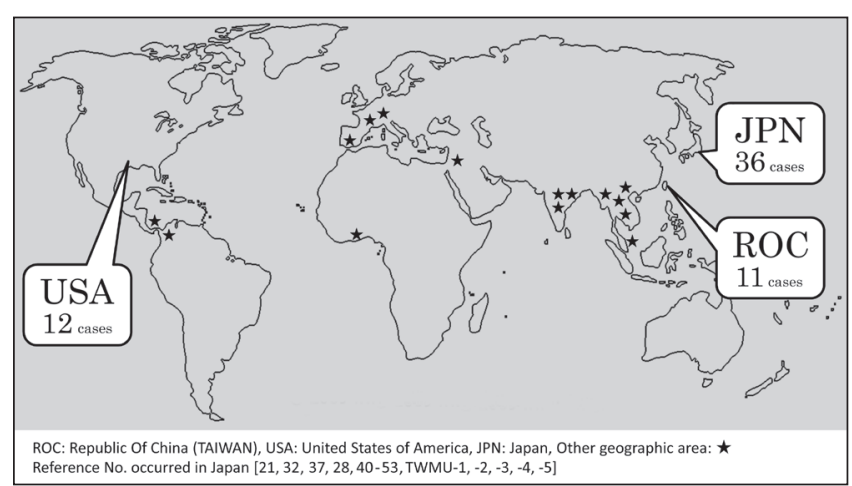

Figure 1) Number (No) of Edwardsiella tarda bacteremia cases according to location on the world map. TWMU Tokyo Women's Medical University, Tokyo, Japan

Ecuador (45) and unpasteurized goat's milk (46). The geographical distribution of ETB is shown in Figure 1. The most frequently reported geographical area of ETB cases was Japan (35 of 77 [45.5\%]) $(21,32,37,40-53)$ (TWMU-1, $-2,-3,-4,-5$ in Table 2), followed by the United States (US) (12 of 77 [15.6\%]) and the Republic of China (Taiwan) (10 of 77 [13.0\%]). Five of $12(41.6 \%)$ cases from the US occurred in states located around the Gulf of Mexico (Louisiana, $n=2$ [12,32]; Florida, $n=1$ [15]; Texas, $n=1$ [18]; and Mississippi, $n=1$ [24]). Of the cases from the US, $66.7 \%$ (eight of 12 ) occurred in states by the ocean (five cases near the Gulf of Mexico (12,15,18,24,32); New York, $\mathrm{n}=2$ [22,33]; and California, $\mathrm{n}=1$ [13]). No reports of ETB cases in the southern hemisphere were found in the present review. The seasonal distribution of ETB is shown in Figure 2. The majority of the cases that provided a description of the time of onset (18 of 22 [81.8\%]) $(10,12,13,15,16,18,21,25,28,33,38,40-42,45,50,51)$ (TWMU-1, - 2, - -3, $-4,-5$ in Table 2) occurred during the northern hemisphere summer and autumn months (June to November).

\section{DISCUSSION}

To our knowledge, the present study was the first and largest multi-language review of ETB. The results indicate that the overall mortality related to ETB is $44.6 \%$, and ETB may be more likely to occur in the humid and subtropical climates of Eastern Asia and near the Gulf of Mexico in the US, particularly during summer and autumn months. Furthermore, environmental and dietary risk factors, such as exposure to brackish water and raw food consumption, may play a role in ETB.

ETB occurs infrequently $(<5 \%)(9)$, and the risk factors are not well established. Investigating similarities with other species may provide some clues regarding the mechanisms related to ETB. Previous case series suggest that up to $50 \%$ of ETB patients also had hepatobiliary diseases, including alcoholic cirrhosis (9). Interestingly, the authors indicated that conditions resulting in iron overload, such as cirrhosis, sickle cell anemia, leukemia and the neonatal state, are also considered to be risk factors for ETB (9). In the present analysis, $66.2 \%$ of the cases involved hepatobiliary diseases, including cancer. Twenty-one $(27.3 \%)$ of these cases involved gallbladder stones with recurrent episodes of cholecystitis. The rate of underlying diseases may be higher in ETB than in other $E$ tarda infections; this may indicate that the presence of underlying disease increases the risk for developing ETB. However, the results of our multivariate analyses suggest, for the first time, that liver cirrhosis is an independent risk factor associated with death in ETB. Cholecystitis with gallbladder stones may increase the risk for ETB in a way similar to that of human typhoid fever. Moreover, the overall rate of underlying diseases in ETB may be higher than in other E tarda infections, potentially indicating that the presence of underlying disease increases the risk for ETB and subsequent high mortality from ETB.

In addition, reservoir-related Aeromonas species are similar to E tarda. Both can cause a wide spectrum of diseases among warm- and cold-blooded animals, including fish, reptiles, amphibians, mammals and humans. Population sizes of both species can grow quite large, generally peaking in the warmer temperatures of the summer months in temperate freshwater lakes and chlorinated drinking water, and have been associated with contact wtih reptiles, including those kept as pets (54). Vibrio vulnificus can also cause severe disseminated infection associated with exposure to seawater and brackish water. Severe $V$ vulnificus infections in humans are also responsible for liver cirrhosis. Therefore, clinical characteristics of $E$ tarda infections in humans resemble those of Aeromonas, typhoid fever and V vulnificus infections, and share similar environmental risks. It is well known that necrotizing fasciitis type 3, which is known as a marine infection and can be fatal within $48 \mathrm{~h}$, is caused by Vibrio or Aeromonas species. Therefore, it should be recognized that $E$ tarda can also result in necrotizing fasciitis type 3 . In addition, previous reports indicate that the mortality rate of ETB is nearly $50 \%$, which is similar to that of $V$ vulnificus (55) or severe infections caused by Aeromonas species $(56,57)$.

E tarda infections, including ETB, are considered to be foodborne. Despite this, dietary risk factors for ETB have not been well established or documented. In addition, most of the cases of ETB are suspected to occur endogenously through primary colonization and infection in the human intestinal tract. However, documented $E$ tarda infections in humans have resulted from the consumption of infected or contaminated food such as fish (58). According to the Food and Agriculture Organization of the United Nations Statisitcs Division (FAOSTAT) Food Balance Sheet 2006 (http://faostat.fao.org/), Japan has one of the world's highest per capita seafood consumption rates. $E$ tarda has been isolated from raw flounder in Japanese fish farms (58). Interestingly, E tarda has been reported to result in a $60 \%$ to $90 \%$ mortality rate among Japanese eels (59), and a traditional custom in Japan, dating from the 18th century, is to eat cooked eel at the end of July. Furthermore, $71 \%$ of the eels from the eel farms in Korea (60) have been reported to carry $E$ tarda.

Toward the end of the 1960s in the US, E tarda was linked to catfish, mainly in the waters of Arkansas, Mississippi, Texas and Louisiana (61). Despite the small number of cases in the current study, approximately one-half of the cases occurred around the Gulf of Mexico, which receives a supply of nutrient-rich water from several rivers. Individuals residing in these areas may be exposed to high concentrations of $E$ tarda through the water or contaminated food. According to data from the National Fisheries Institute, tilapia, pangasius and catfish are consumed in the US. They are farmed in fresh water and $79 \%$ of already-dressed catfish in the US carry E tarda (62). Given the collective findings of the available literature, we suspect that dietary exposures also affect the risk for ETB.

Little is known about the recent prevalence of $E$ tarda colonization in healthy individuals; no recent data are available from large-scale studies in any country. A study conducted in the 1970s (7), is one of the few to report that only 26 of 353,600 Japanese individuals were healthy carriers of $E$ tarda. We suspect that the rate of colonization in stool appears to be high among individuals in areas with a high consumption of raw fish contaminated with $E$ tarda. The colonization rate in humans may be affected by changes in dietary habits and increased travel, and the use of novel techniques, such as matrix-assisted laser desorption ionization-time of flight mass spectrometry, may improve identification of $E$ tarda, which was previously underestimated.

Trimethoprim/sulfamethoxazole-resistant $E$ tarda has been clinically isolated in a pediatric patient with X-linked chronic granulomatous disease and osteomyelitis in Japan (63). No multidrug-resistant strains of E tarda were found in the current study. There are several studies showing at least $90 \%$ of $E$ tarda strains to be colistin resistant. Natural resistance of $E$ tarda to colistin or polymyxin B has been suggested, but its mechanism was unelucidated (64). Feedstuffs for domesticated animals are exposed to colisin in Japan (65) and some European countries. Antibiotic resistance in E tarda may emerge as an issue related to environmental antibiotic exposure in food production. Geographical differences among the Republic of China (Taiwan) 


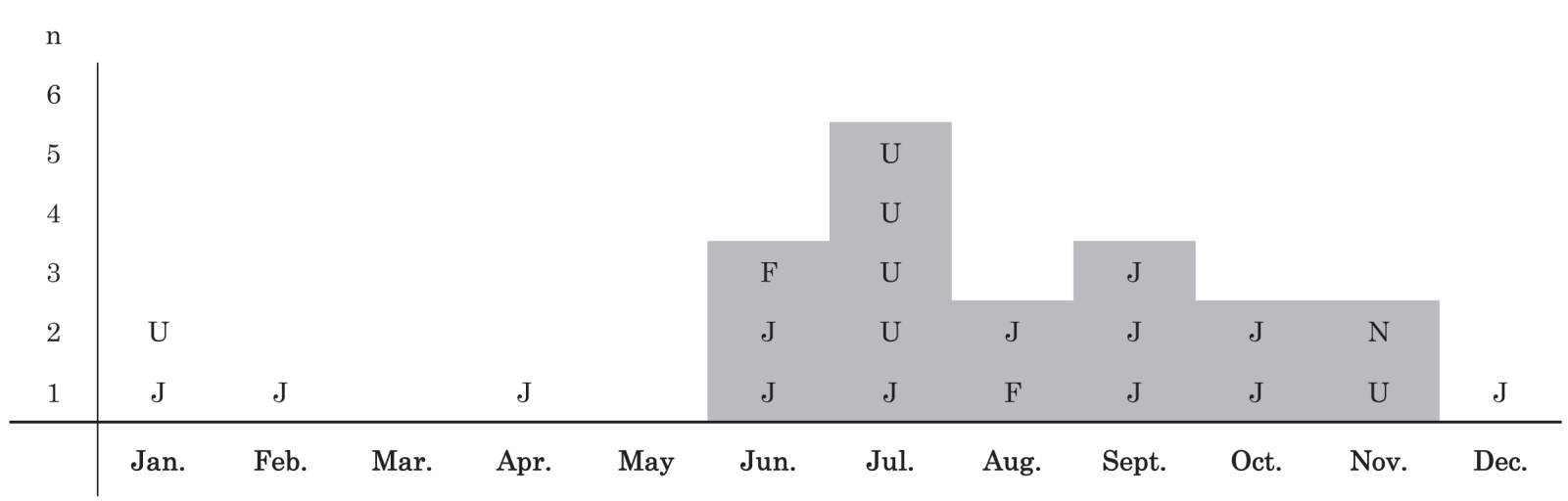

\section{F: France, J: JAPAN, N: Nigeria, U: United States of America}

Figure 2) The seasonal distribution of 22 Edwardsiella tarda bacteremia cases. Apr April; Aug August; Dec December; Feb February; Jan January; Jul July; Jun June; Mar March; Oct October; Sept September; Nov November

and the US in the antimicrobial susceptibility of E tarda, isolated from food-producing animals, have been previously described (66). Seasonal distribution of human E tarda gastroenteritis has not been previously demonstrated (9). In addition, information has not been available regarding the time of year for extraintestinal $E$ tarda infections in previously reported cases. The results of the current review suggest that there may, in fact, be a seasonal distribution of ETB, and exposure to higher concentrations of $E$ tarda in the warmer temperatures of the summer months may increase the risk for ETB (61). For example, Eastern Asia, which includes Japan and the Republic of China (Taiwan), and the states of the US near the Gulf of Mexico, reported the highest rates of ETB and belong to climates that are similar - humid and subtropical.

In addition, dietary customs vary according to geographical region. Therefore, dietary factors may play a role in the geographical or seasonal distributions of ETB.

Taking all of this into account, we propose two reasons for the high prevalence of ETB in Japan. The first is that Japan is geographically rich in brackish water areas and rivers. Second, the Japanese consume a relatively large amount of raw seafood, which may be contaminated with E tarda.

\section{REFERENCES}

1. Trabulsi LR, Ewing WH. Sodium acetate medium for the differentiation of Shigella and Escherichia cultures. Public Health Lab 1962;20:137-40.

2. King BM, Adler DL. A previously undescribed group of Enterobacteriaceae. Am J Clin Pathol 1964;41:230-2.

3. Sakazaki R. A proposed group of the family Enterobacteriaceae, the Asakusa group. Int Bull Bacteriol Nomencl Taxon 1965;15:45-7.

4. Ewing WH, McWhorter AC, Escobar MR, Lubin AH. Edwardsiella, a new genus of Enterobacteriaceae, based on a new species, E.tarda. Int Bull Bacteriol Nomencl Taxon 1965;15:33-8.

5. Wyatt LE, Nickelson R, Vanderzant C. Edwardsiella tarda in freshwater catfish and their environment. Appl Environ Microbiol 1979;38:710-4.

6. Joh SJ, KIM MJ, Kwon HM, Ahn EH, Jang H, Kwon JH. Characterization of Edwardsiella tarda isolated from farm-cultured eels, Anguilla japonica, in the Republic of Korea. J Vet Med Sci 2011;73:7-11.

7. Onogawa T, Terayama T, Zenyoji H. Distribution of Edwardsiella tarda and hydrogen sulfide-producing Escherichia coli in healthy persons. J Jpn Assoc for Infect Dis (Kansenshogaku Zasshi) 1976;50:10-7

8. Kournay M. Vasquez MA, Saenz R. Edwardsiellosis in man and animals in Panama: Clinical and epidemiological characteristics. Am J Trop Med Hyg 1977;26:1183-90.
The present review had limitations. One was the retrospective nature of the data, including the use of previously reported literature and only five recent cases from our institute. Fourteen of 72 cases from the literature were described only in the Japanese language. Therefore, publication and resource bias may have affected our results. The second limitation is that we focused on the results of blood cultures; however, sensitivity of blood cultures may vary during a long study period.

\section{CONCLUSIONS}

ETB may be categorized as a severe food-and waterborne infection similar to Aeromonas, Vibrio and Salmonella (typhoid fever) infections, which result in high mortality in patients with severe underlying diseases such as liver cirrhosis. Geographical and seasonal distributions may characterize ETB. The clinical epidemiology, including dietary risk factors and the current incidence of ETB should be further established.

DISCLOSURES: The authors have no financial relationships or conflicts of interest to declare.

ACKNOWLEDGEMENTS: Results from this study were presented, in part, as a poster (Presentation number 1263) at ID Week 2013, San Francisco, October 2 to 6, 2013.

9. Janada JM, Sharon LA. Infections associated with the genus Edwardsiella: The role of Edwardsiella tarda in human diseases. Clin Infect Dis 1993;17:742-8.

10. Okubadejo OA, Alausa KO. Neonatal meningitis caused by Edwardsiella tarda. Br Med J 1968;3:357-8.

11. Sonnenwirth AC, Kallus BA. Meningitis due to Edwardsiella tarda. First report of meningitis caused by E.tarda. Am J Clin Pathol 1968;49:92-5.

12. Pankey GA, Seshul MB. Septicemia caused by Edwardsiella tarda. J La State Med Soc 1969;121:41-3.

13. Jordan GW, Hadley WK. Human infection with Edwardsiella tarda. Ann Intern Med 1969;70:283-8.

14. Bockemühl J, Pan-Urai R, Burkhardt F. Edwardsiella tarda associated with human disease. Pathol Microbiol 1971;37:393-401.

15. Sachs JM, Pacin M, Counts GW. Sickle hemoglobinopathy and Edwardsiella tarda meningitis. Am J Dis Child 1974;128:387-8.

16. Le Frock JL, Klainer AS, Zuckerman K. Edwardsiella tarda bacteremia. South Med J 1976;60:188-90.

17. Koshi G, Lalitha MK. Edwardsiella tarda in a variety of human infections. Indian J Med Res 1976;64:1753-9.

18. Clarridge JE, Musher DM, Fainstein V, Wallace RJ Jr. Extraintestinal human infection caused by Edwardsiella tarda. J Clin Microbiol 1980;11:511-4. 
19. Ovartlarnporn B, Chayakul P, Suma S. Edwardsiella tarda infection in Hat Yai Hospital. J Med Assoc Thai 1986;69:599-603.

20. Marínez ML, Lázaro ME, Albillos A, et al. Edwardsiella tarda bacteremia. Eur J Clin Microbiol Infect Dis 1987;6:599-600.

21. Funada H, Kameoka J, Machi T, Matsuda T. Edwardsiella tarda septicemia complicating acute leukemia. Jpn J Med 1987;27;325-8.

22. Vohra K, Torrijos E, Jhaveri R, Gordon H. Neonatal sepsis and meningitis caused by Edwardsiella tarda. Pediatr Infect Dis J 1988;7;814-15.

23. Wilson JP, Waterer RR, Wofford JD, Chapman SW. Serious infections with Edwardsiella tarda. A case report and review of the literature. Arch Intern Med 1989;149:208-10.

24. Jaruratanasirikul S, Kalnauwakul S. Edwardsiella tarda: A causative agent in human infections. Southeast Asian J Trop Med Public Health 1991;22:30-4.

25. Fournier S, Pialoux G, Feuillie V, Fleury J, Dupont B. Edwardsiella tarda septicemia with cellulitis in a patient with AIDS. Eur J Clin Microbiol Infect Dis 1997;16:551-3.

26. Osiri M, Tantawichien T, Deesomchock U. Edwardsiella tarda bacteremia and septic arthritis in a patient with diabetes mellitus. Southeast Asian J Trop Med Public Health 1997;28:669-72.

27. Yang CH, Wang CK. Edwardsiella tarda bacteraemia-complicated by acute pancreatitis and pyomyoma. J Infect 1999;38:124-6.

28. Slaven EM, Lopez FA, Hart SM, Sanders CV. Myonecrosis caused by Edwardsiella tarda: A case report and case series of extraintestinal E.tarda infections. Clin Infect Dis 2001;32:1430-3.

29. Mowbray EE, Buck G, Humbaugh KE, Marshall GS. Maternal colonization and neonatal sepsis caused by Edwardsiella tarda. Pediatrics 2003;111:e296-8.

30. Wang IK, Kuo HL, Chen YM, et al. Extraintestinal manifestations of Edwardsiella tarda infection. Int J Clin Pract 2005;59:917-21.

31. Yousuf RM, How SH, Amran M, Hla KT, Shah A, Francis A. Edwardsiella tarda septicemia with underlying multiple liver abscesses. Malays J Pathol 2006;28:49-53.

32. Tamada T, Koganemaru H, Matsumoto K, Hitomi S. Urosepsis caused by Edwardsiella tarda. J Infect Chemother 2009;15:191-4.

33. Golub V, Kim AC, Krol V. Surgical wound infection, tuboovarian abscess, and sepsis caused by Edwardsiella tarda: Case reports and literature review. Infection 2010;38:487-9.

34. Kadam SD. Edwardsiella tarda - a case report. Indian J Pediatr 2013;80:63-4.

35. Hashavya S, Averbuch D, Berger I, et al. Neonatal sepsis following maternal amnionitis by Edwardsiella tarda: A case report and a review of the literature. Eur J Pediatr 2011;170:111-3.

36. John AM, Prakash JA, Simon EG, Thomas N. Edwardsiella tarda sepsis with multiple liver abscesses in a patient with Cushing's syndrome. Indian J Med Microbiol 2012;30:352-4.

37. Ohara Y, Kikuchi O, Goto T, et al. Successful treatment of a patient with sepsis and liver abscess caused by Edwardsiella tarda. Intern Med 2012;51:2813-7.

38. Peyrade F, Bondiau P, Taillan B, Boscagli A, Roa M, Dujardin P. Edwardsellia tarda septicemia in chronic lymphoid leukemia. Rev Med Interne 1997;18:233-4.

39. Perez RDA, Ramirez AG. Sepsis por Edwardsiella tarda y asociación conanemia falciforme: Reporte de caso y revision de la literature. Medicina \& Laboratorio 2008; $14: 43-8$.

40. Mori K, Yamazaki A, Kishikawa E, Sugizaki N, Kume H. A case of sepsis caused by Edwardsiella tarda. J Jpn Assoc Infect Dis (Kansenshogaku Zasshi) 1983;57:273-9.

41. Harada M, Yoshida H, Oomagari K, Sakai T, Abe H, Tanikawa K. A case of sepsis caused by Edwardsiella tarda complicated panophthalmitis and pyogenic spondylitis.

J Jpn Assoc Infect Dis (Kansenshogaku zasshi) 1990;64:620-4.

42. Matsushima S, Yajima S, Taguchi T, et al. A fulminating case of Edwardsiella tarda septicemia with necrotizing fasciitis.

J Jpn Assoc Infect Dis (Kansenshogaku zassshi) 1996;70:631-6.

43. Tohira H, Yokota J. Edwardsiella tarda. Nihon rinsho 2001;(Suppl 1):235-8.
44. Maruge S, Mizuguchi M, Yasuda T, et al. A case of necrotizing fasciitis with septic shock due to Edwadsiella tarda.

J Jpn Assoc Infect Dis (Kansenshogaku Zasshi) 2005;79(Suppl 1):228.

45. Fujimoto M, Nakao K, Fujikawa K, et al. A case of rapidly progressive fatal septic shock following necrotizing fascilitis due to Edwardsiella tarda with hepatitis $\mathrm{C}$ virus related liver cirrhosis complicated hepatocellarcarcinoma Kanzo 2006;47:273-4.

46. Nishiyama H, Tarumoto K, Fujikawa K. A case of necrotizing fasciitis due to Edwardsiella tarda. J Jpn Soc Clin Microbiol 2007;17(Suppl 1):130.

47. Takahashi K, Ikeda M, Matsubayashi $\mathrm{H}$, et al. Intrauterine infection caused by Edwardsiella tarda. Kanto Journal of Obstetrics and Gynecology 2007;44:73-6.

48. Tamura T, Ito K, Tsuchiya R, et al. A case of septic shock with necrotizing fascilitis caused by Edwardsiella tarda. J Jpn Soc Care Med 2009;16:207-8.

49. Fujii M, Ooki T, Yoshiko M. A case of necrotizing fasciculitis caused by E.tarda in a patient with peritoneal dialysis. J Jpn Soc Dial Ther 2009; (Suppl 42):739.

50. Hara K, Ouchi H, Kitahara M, Shibano K, Miyauchi T, Ishiguro H. A case of fasciitis localized in the calf muscles associated with Edwardsiella tarda sepsis. Clin Neurol (Rinsho Shinkeigaku) 2011;51:694-8.

51. Tokunaga S, Tanino T, Koda M, et al. A case of sepsis due to Edwardsiella tarda with alcoholic liver cirrhosis complicated by hepatocellular carcinoma and lung cancer. Kanzo 2011;52:120-5.

52. Sato M, Satomura H, Odaka I. Septic shock caused by Edwardsiella tarda. Journal of Chiba Association of Medical Technologists 2012;115:56-9.

53. Tanaka C, Nishikawa N, Mushika M, et al. Intrauterine infection which caused sepsis by Edwardsiella tarda. Tokai J Obstet Gynecol 2013;49:285-9.

54. Nagel P, Serritella A, Layden TJ. Edwardsiella tarda gastroenteritis associated with a pet turtle. Gastroenterology 1982;82:1436-7.

55. Matsumoto K, Ohshige K, Fujita N, et al. Clinical features of Vibrio vulnificus infections in the coastal areas of the Ariake Sea, Japan. J Infect Chemother 2010;16:272-9.

56. Wang JH, Wang CY, Chi CY, Ho MW, Ho CM, Lin PC. Clinical presentations, prognostic factors, and mortality in patients with Aeromonas sobria complex bacteremia in a teaching hospital: A 5-year experience. J Microbiol Immunol Infect 2009;42:510-5.

57. Dryden M, Munro R. Aeromonas septicaemia: Relationship of species and clinical features. Pathology 1989;21:111-4.

58. Rashid MM, Honda K, Nakai T, Muroga K. An ecological study on Edwardsiella tarda in flounder farms. Fish Pathology 1994;29:221-7.

59. Kim KI, Kang JK, Park JY, Joh SJ, Lee HS, Kwon YK. Phenotypic traits, virulence-associated gene profile and genetic relatedness of Edwardsiella tarda isolates from Japanese eel Anguilla japonica in Korea. Lett Appl Microbiol 2014;58:168-76.

60. Joh SJ, Ahn EH, Lee HJ, Shin GW, Kwon JH, Park CG. Bacterial pathogens and flora isolated from farm-cultured eels (Anguilla japonica) and their environmental waters in Korean eel farms. Vet Microbiol 2013;163:190-5.

61. Meyer FP, Bullock GL. Edwardsiella tarda, a new pathogen of channel catfish (Ictalurus punctatus). Appl Microbiol 1973;25:155-6.

62. Wyatt LE, Ranzell N, Vanderzant C. Edwardsiella tarda in freshwater catfish and their environment. Appl Environ Microbiol 1979;38:710-4.

63. Kawai T, Kusakabe H, Seki A, Kobayashi S, Onodera M. Osteomyelitis due to trimethoprim/sulfamethoxazole-resistant Edwardsiella tarda infection in a patient with X-linked chronic granulomatous disease. Infection 2011;39:171-3.

64. Muyembe T, Vandepitte J, Desmyter J. Natural colistin resistance in Edwardsiella tarda. Antimicrob Ag Chemother 1973;4:521-4.

65. Marshall BM, Levy SB. Food animals and antimicrobials: Impacts on human health. Clin Microbiol Rev 2011;24:718-33.

66. Waltman WD, Shotts EB. Antimicrobial susceptibilities of Edwardsiella tarda from the United States and Taiwan. Vet Microbiol 1986;12;277-82. 


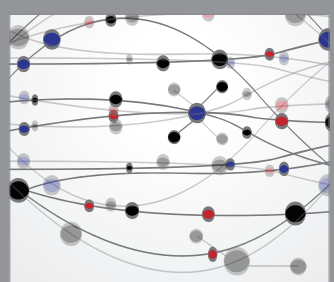

The Scientific World Journal
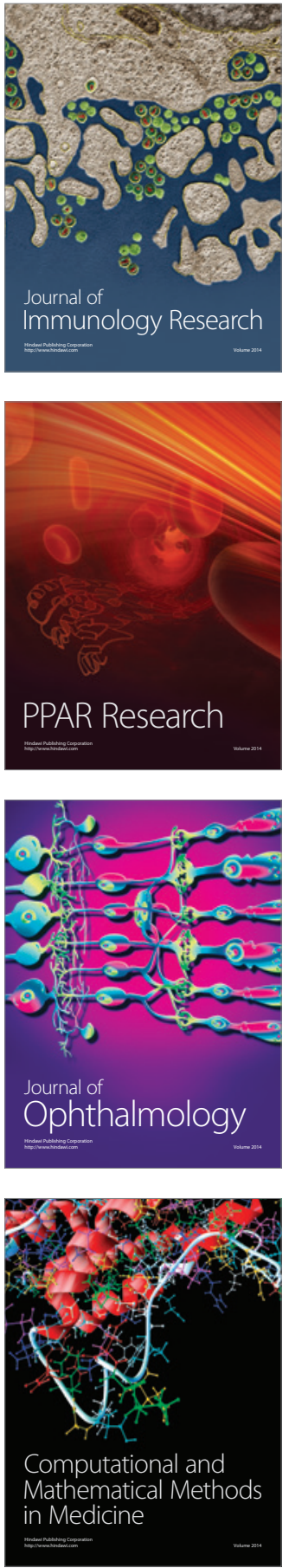

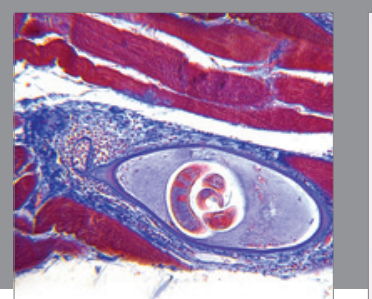

Gastroenterology Research and Practice

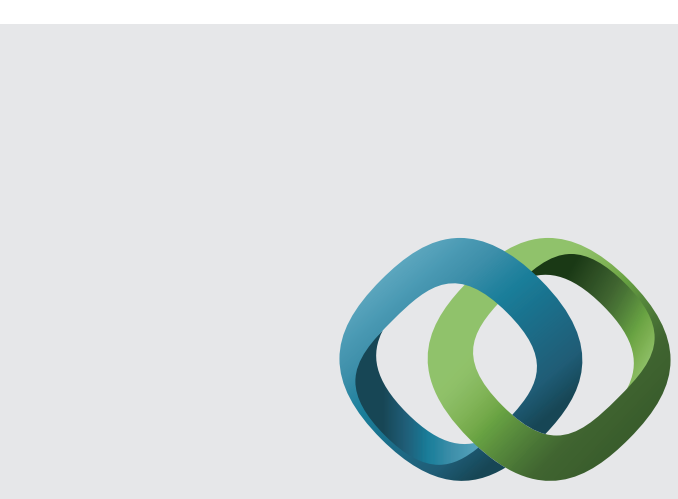

\section{Hindawi}

Submit your manuscripts at

http://www.hindawi.com
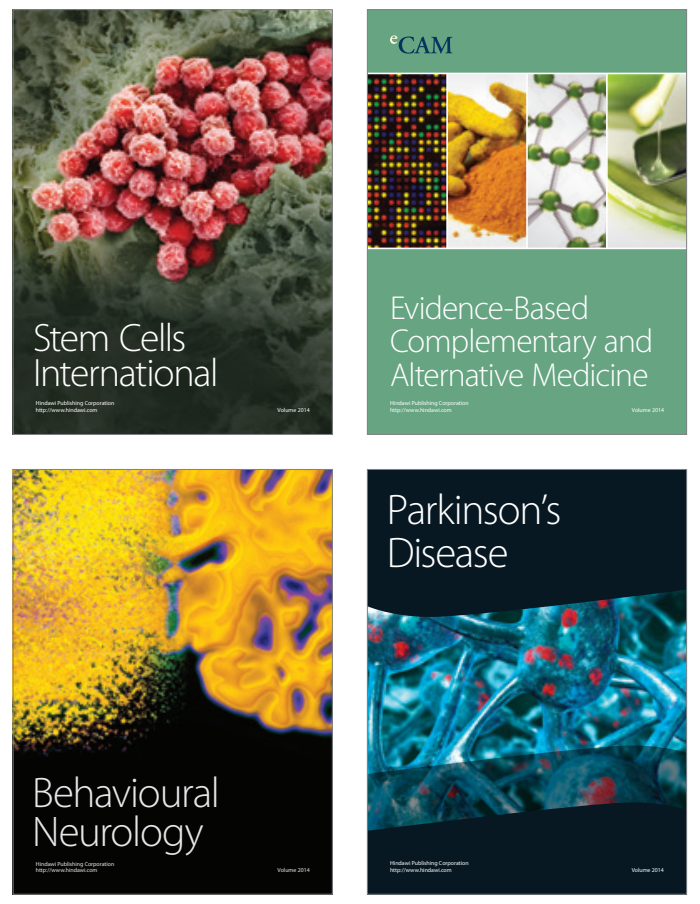
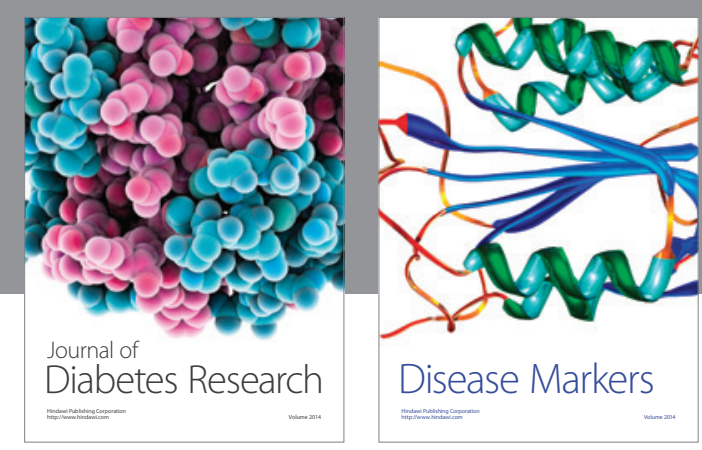

Disease Markers
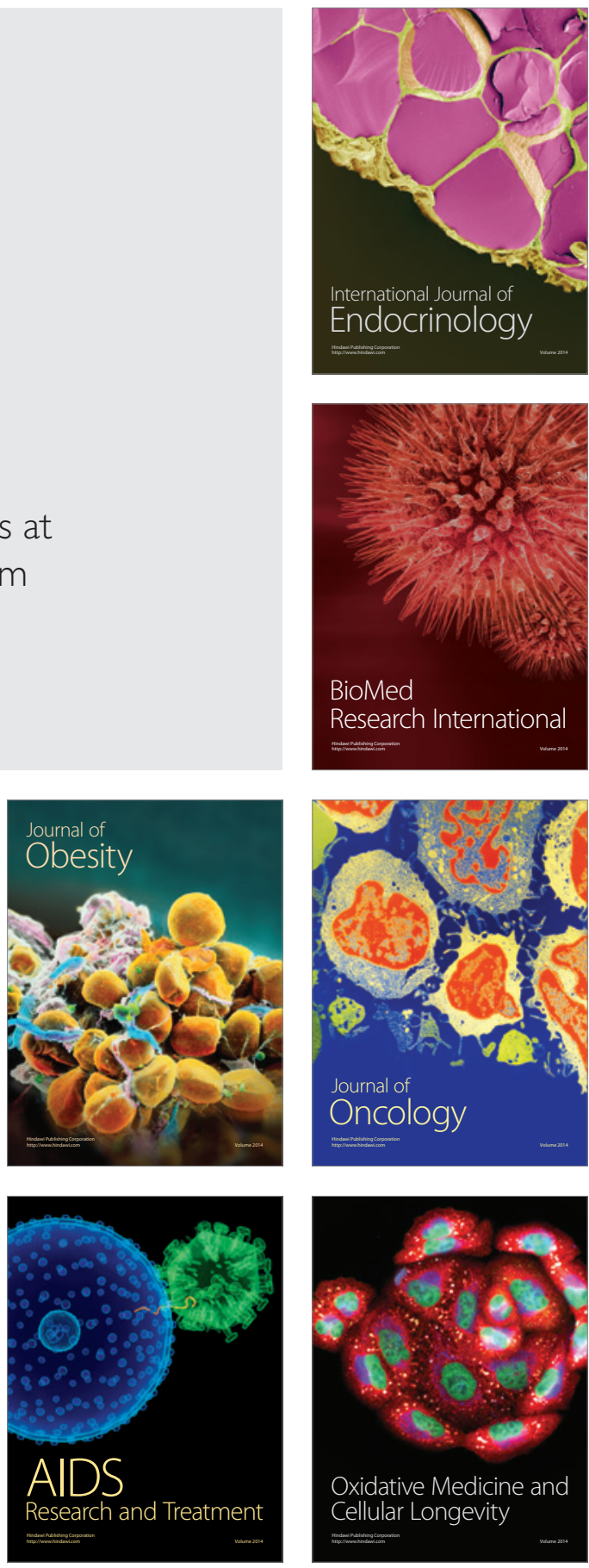